\title{
THE PAN-AFRICAN CONGRESS ON PREHISTORY
}

\section{$\mathrm{T}$} HOSE who are not well acquainted with the fields of prehistory and allied studies will scarcely be aware of the great developments which have recently taken place in these subjects in different parts of Africa. It is true to say, however, that as the result of the enthusiastic work of archæologists, palæontologists and geologists throughout that Continent, a vast mass of evidence has now been collected. having the most important bearing on fundamental problems of human evolution and the development of early cultures. But much of this evidence has been assembled independently in widely separated regions of the Continent, and for some time it has been recognized that further progress might be seriously impeded if the relative isolation of prehistorians in different parts of Africa were to continue. It was mainly for this reason that the idea of a Pan-African Congress on Prehistory was conceived and put into effect by Dr. L. S. B. Leakey, curator of the Coryndon Memorial Museum in Nairobi. In spite of transport and other difficulties, the Congress has met with very considerable success, for it was attended by more than sixty delegates representing all the African territories as well as many European countries.

The Pan-African Congress was formally opened in the Town Hall of Nairobi on January 14 by the Governor of Kenya, Sir Philip Mitchell, and the proceedings were broadcast. The Abbé Breuil was unanimously elected president of the Congress, and Dr. R. Broom the vice-president. Meetings were held in the Town Hall and were continued from January 14 until January 23, during which many papers were read and discussed. For convenience, the business of the Congress was divided into three sections : (1) Geology, Climatology, and General Palæontology (chairman, Prof. A. L. du Toit); (2) Archæology (chairman, Dr. L. S. B. Leakey); and (3) Human Palæontology (chairman, Prof. R. Dart).

In the first section, interest tended to be focused largely on chronological problems, and particularly on the relation of early man in Africa to climatic fluctuations, faunal sequences, relative changes of land-and sea-levels, and geological events such as the formation of the Great Rift Valley. The Quaternary fauna of the African Continent was discussed in illuminating papers by Prof. C. Arambourg and Dr. B. S. Cook, and interesting points in the faunal correlation between Pleistocene Africa and Ceylon were made by Prof. P. Deraniyagala. The problem of the Plio-Pleistocene boundary was raised by Prof. F. Zeuner-an important problem in any attempt at a correlation of quaternary sequences in the African Continent with those in other parts of the world. Other papers dealing with the relation of geology to prehistory included a study of the development of the Sudan Plain in the quaternary by Mr. G. Andrew, a discussion of the recent physiographic history of the Lower Nile Valley in relation to pluvial oscillations in Abyssinia by Dr. S. A. Huzayyin, and an account of the high-level beaches of the Tanganyika lakes by Dr. D. R. Grantham. An interesting symposium was also held on the relation of pleistocene marine terraces to Stone Age cultures, with the main contributions by the Abbé Breuil, Prof. Zeuner and Dr. A. Ruhlmann, and a general discussion was held on the whole question of the Pleistocene in Africa with special reference to the dating of deposits and the devising of a unified terminology for describing the Pluvial Periods.

In the section on archæology, a number of delegates from different parts of Africa contributed an account of Palæolithic culture sequences in their own particular areas as a preliminary to a general discussion on terminology. Mr. A. J. Arkell dealt with the Lower Palæolithic of the, Anglo-Egyptian Sudan, Mr. A. J. Wayland with the Stone Age in Bechuanaland, Mr. Neville Jones with the Stone Age in Southern Rhodesia, Mr. Desmond Clark with the chronology of the Stone Age in Somaliland and Northern Rhodesia, Dr. Ruhlmann with Moroccan Palæolithic cultures, Prof. C. Van Riet Lowe with the development of the Great Hand Axe culture in South Africa, Dr. B. D. Malan with the Middle Stone Age culture in South Africa, and Dr. Leakey with the Tumbian culture of East Africa. One morning's session was also devoted to a series of papers on rock paintings.

In the section on human palæontology the papers included an important survey by Dr. L. H. Wells on the human remains of the Middle Stone Age in South Africa, but interest was mainly focused on the fossil Australopithecine apes from South Africa and the Miocene apes from Kenya. Prof. Le Gros Clark (who immediately before the Congress had been able to visit South Africa in order to examine the important Australopithecine material in the Transvaal Museum at Pretoria and the University of the Witwatersrand at Johannesburg) gave an account of the results of his studies. The main points of this communication were as follows. There is no evidence that the Australopithecinæ bear any close relationship to the African anthropoid apes of to-day, other than that which is implied by the fact that they are both hominoids* of comparable size. The suggestion that the Australopithecinæ are to be regarded as anthropoid apes which, in certain anatomical features, had undergone a parallel or convergent evolution leading to a secondary but independent development of certain human resemblances must almost certainly be ruled out, for the morphological similarities to the Hominidæ in the skull, dentition, and limbs seem far too numerous, detailed and intimate to permit of such an interpretation. These similarities include the pattern, proportions and disposition of the teeth, the detailed construction of the supraorbital region, zygomatic bone, temporo-mandibular articulation and auditory region, the position and size of the foramen magnum, the contours of the maxilla and mandible, and the details of certain small foramina in the skull. Other remarkable points are the degree of wear of the milk molars in Australopithecus, and the fact that in the type Plesianthropus skull the sagittal and coronal sutures were still completely patent although the third permanent molars had fully erupted and already showed signs of wear. These points seem to indicate quite clearly a prolongation of the growth period in the Australopithecinæ comparable to that of man. The fragments of the limb skeleton which have so far been discovered

* The term 'hominoid' is here used in reference to Simpson's superfamily Hominoidea, which includes man and the anthropoid apes (see his recently published "Classiflcation of Mammals"). 
present surprising features, for the lower end of the humerus and upper end of the ulna ascribed to Paranthropus, and the lower end of the femur and the capitate bone ascribed to Plesianthropus, would by themselves have been unhesitatingly ascribed to Homo sapiens (though a detailed metrical analysis might reveal slight differences in comparison with modern races of man). On the other hand, the talus (astragalus) of Paranthropus provides evidence of a degree of mobility of the front part of the foot considerably exceeding that found in Homo. The femoral fragment ascribed to Plesianthropus clearly indicates a completely erect posture and gait, probably associated with a rather wide pelvis.

The combination of limb bones so human in their anatomical details with a brain development scarcely exceeding that of the gorilla or chimpanzee (so far as this can be determined from endocranial casts) must inevitably raise the question whether the limb bones are correctly to be associated with the fossil remains of the skulls. But the circumstances in which they were found, together with the similar degree of fossilization, and Dr. Broom's affirmation of the complete absence of any signs of human occupation from the deposits at Sterkfontein and Kromdraai, as well as the complete absence of any remains of skulls or teeth of Homo, seem to leave no doubt about the correctness of the association. If this is really the case (and any possible doubts that may remain are likely to be settled soon by excavations now in progress), the conclusions to be drawn are of the greatest significance for the study of human evolution. It must be inferred, for example, that in the evolutionary sequence, limbs approximating to a human type had already been acquired at a time when the brain was still of simian proportions. At this phase of development also, the dentition had a definitely human appearance rather than that characteristic of the recent anthropoid apes. The Australopithecine material, indeed, supports the inferences drawn from the indirect evidence of comparative anatomy that many of the diagnostic characters of the recent large anthropoid apes, such as the powerful canines and the large incisors (accompanied by the 'simian shelf' in the mandible), the exaggerated development of the supra-orbital torus, the construction of the powerful brachiating arms, and certain features of the hindlimbs, are to be regarded as aberrant specializations peculiar to these apes and not as primitive features to be sought for in human ancestry. Finally, the morphological evidence of the South African fossils makes it tolerably certain that the point of divergence of the human line of evolutionary development from the line leading to the modern large anthropoid apes must be assigned to a geological date considerably earlier than many palæontologists have hitherto been prepared to accept.

In the course of his report, Prof. Le Gros Clark paid a tribute to the pioneer work of Prof. Raymond Dart of the University of the Witwatersrand, who, in 1925, was the virtual discoverer of the type specimen of the Australopithecinæ, and to Dr. R. Broom, who was responsible for the further discoveries, the results of which have been published in his recent monograph (see Nature, June 29, 1946, p. 863). There appeared no room for doubt that Dart and Broom had certainly not over-estimated the significance of the Australopithecinæ, and that their interpretations of these fossil remains were entirely correct in all essential details. However, the allocation of the Australopithecine fossils to an early Pleistocene, or even to a late Pliocene, date would mean that they could not themselves represent the ancestral stock from which the Hominidæ were derived. But they were almost certainly to be regarded as late, and only slightly modified, survivals of that ancestral stock.

The remains of Miocene Hominoidea in Kenya (particularly at Rusinga and Songhor) are interestingly complementary to the South African fossils, for while the latter have a specific reference to the evolution of the human line of development, the Kenya material provides important evidence for the evolution of the Hominoidea as a whole, that is, the zoological group of which the human line represents but one offshoot. Dr. Leakey's discovery of further remains of Proconsul, including an almost complete mandible, makes it clear that this extinct form (in spite of some remarkably primitive characters) was closely allied to the Dryopithecine apes. Far more interesting, though perhaps less spectacular, are his discoveries of the teeth and jaws of Xenopithecus and Limnopithecus. The former helps to bridge the morphological hiatus which has hitherto separated the large from the small anthropid apes, and the latter serves to link up the Kenya assemblage of Miocene hominoids with Propliopithecus from the Oligocene of Egypt. Much of this important fossil material has already been described and discussed in an important memoir by Dr. D. G. MacInnes.

A point of great importance which has emerged from the Pan-African Congress is that the deposits in South Africa yielding the Australopithecine material and those in Kenya yielding Miocene hominoids are exceedingly rich in fossil remains, and that systematic excavation in both these regions is practically certain, in a relatively short time, to provide the evidence required to reconstruct much that is still obscure in man's evolutionary history. It was announced at the Congress that an expedition has been organised from the University of California with the purpose of excavating far more thoroughly than hitherto the Sterkfontein and Kromdraai sites in South Africa. A complementary expedition to the Miocene deposits of Kenya in co-operation with Dr. Leakey, financed from Great Britain, was very seriously urged by the British delegates.

The Pan-African Congress on Prehistory included several excursions of great archæological interest. One excursion (lasting two days) was made to the Great Rift Valley as far north as Nakuru. Delegates were taken to the top of the Kinangop plateau, $2,000 \mathrm{ft}$. above the present level of Lake Naivasha, and were able to pick out for themselves from lacustrine deposits on the plateau obsidian points and scrapers of late Middle Pleistocene date. They also visited the obsidian mines (about forty miles distant on the other side of the Great Rift Valley) from which early man obtained his raw material. At the Kariandusi River site (near Lake Elmenteita) they inspected what was evidently a factory of handaxes of the Acheulean type, and a visit was made to Gamble's cave, on the Mau escarpment, where remains of Aurignacian man had been found. On January 19 an excursion was made to the Acheulean site at Olorgesailie, discovered by Mrs. Leakey in 1942. Here the delegates were astonished to see hundreds of hand-axes and cleavers strewn over the eroded slopes of Pleistocene lacustrine deposits. Trenches had been cut which showed that several camp sites had here succeeded each other on a series of ancient land surfaces (interbedded between lake 
clays). In these deposits were found large numbers of implements, groups of 'bolas' stones, and remains of the giant baboon (Simopithecus), giant pig, and other extinct mammals. The whole of this site has been fenced off and partly roofed over to provide a local field museum. On the occasion of this excursion, the museum was formally opened to the public by Sir Gilbert Rennie, Chief Secretary of Kenya. Finally, at the end of the Congress, a seven-day tour was made to Arusha, Ngorongoro and the Olduvai Gorge.

It has already been mentioned that the PanAfrican Congress on Prehistory was a success. It was, in fact, an outstanding success in several ways. Apart from the value of the actual scientific meetings and the interchange of ideas between prehistorians from different parts of Africa and elsewhere, the discussions led to some very important agreements with regard to terminology and also with regard to plans for co-ordinated research in the future. Finally, it was decided to set up a permanent organisation and to hold a Pan-African Congress on Prehistory every four years. At the invitation of Field-Marshal Smuts, the next Congress is to be held in South Africa in 1951.

At the final myeting of the Congress, votes of thanks were passed to the Governor of Kenya and the Kenya Government for their sponsorship of the Congress, to the people of Nairobi who had given hospitality to the delegates, and to the organising secretary, Dr. Leakey as the result of whose enthusiasm and energy the idea of the Congress had been initiated and so successfully carried out

\section{PALAOLITHIC HUMAN REMAINS IN ASIA}

$T$ HE discovery of the skeleton of a child, reported to be a representative of the "Neanderthal" type, in a deposit in the Teshik-Tash Cave, near Bokhara, in Southern Uzbekistan, is a matter of considerable interest to anthropologists. The age of the individual is said to have been about eight or nine years, and the discovery was made in the course of systematic excavation by archæologists. They refer to the deposit as "middle palæolithic", and this would presumably include a Mousterian subdivision. The discovery is particularly interesting, since if confirmed it will extend very considerably eastwards the area of geographical distribution of the Neanderthal type.

Apart from discussion of the immediate surroundings and their antiquity, the characters of the skeleton are in themselves noteworthy. Dr. Weidenreich, of the American Museum of Natural History, has conferred a great benefit on students who are unable to consult the original version of the description (in Russian), by means of his eritical account in the American Journal of Physical Anthropology (N.S. 3, No. 2, June 1945). The net result is a plea for re-examination of the skeleton, and if that be granted, the facts submitted by Dr. Weidenreich will necessarily elaim further attention.

Actually Dr. Weidenreich states that he "is not convinced that the Uzbek skull is an immature Neanderthal skull belonging to the European varia. tion", nor, he adds. "of the Mousterian European type"; and he sets out the data on which that opinion is based.

At this point it should be noted that the child's skull is said to have been "smashed into more than 150 fragments", from which it has been reconstructed. Moreover, the Russian observers are not quite unanimous in their opinions, though examination of the original documents in Russian might reduce any seeming discrepancy. But in consideration of the information available, it is to be noted that Dr. Weidenreich cites a brief report in $S_{\text {cience }} \mathbf{1}$ by the late Dr. Aleš Hrdlička on the discovery of the skeleton in 1938 by Prof. Okladnikoff. In that report Dr. Hrdlička is said to state that the skull was identified by the discoverers as a "Neanderthal child". Finally, Hrdlička had the opportunity of examining the skull and concluding that some five or six important characters which he cited "all denote unequivocally a Neanderthal specimen".

In the following yer $r$ the Uzbekistan Section of the Academy of Sciences of the U.S.S.R. devoted an entire fascicle to the Uzbek skull (1940). The VOKS Bulletin No. 9/10 for 1945 contains a report on "Recent Work on Soviet Anthropology" by Prof. A. Bunak. In this, Prof. Bunak refers to a compre. hensive monograph "now in press", which may represent an extension of the fascicle of 1940 men. tioned above. However that may be, Prof. Bunak reports that he has taken part in the investigation, having been engaged in examining the brain-cast. In his opinion, the skull is "Neanderthaloid", but he adds that while "this conclusion is beyond doubt, from the modern point of view it is insufficient", and "the extreme youth of the relic renders it difficult to draw a definite conclusion". He concludes that it provides valuable material for "the investigation of the variations of the "Neanderthaloid' type".

In advocating a revision of the rather dogmatic opinion expressed by the late Dr. Hrdlicka, Dr. Weidenreich is not unreasonable. His most effective criticism relates to the form of section of the mandible at the chin. He notes the large 'capacity' assigned to the skull, but on this ground he is less convincing. Reconstruction from so many fragments may be partly responsible, and the same factor may affect a detail to which Dr. Weidenreich might have pointed effectively. This is the more forwardly directed plane of the foramen magnum as exhibited in the tracing of the skull in the sagittal plane.

The main object of this communication is to direct attention to the discussion and to indicate the interest of the specimen to which it is related. Dr. Weidenreich's plea for re-examination is also commended.

In the memoir published in the American Journal of Physical Anthropology (cited above), Dr. Weidenreich renews his support (1928) of the claims made on behalf of the Podkumok skull (Caucasus) for recognition as showing a transition from the Neanderthal type to that of the modern Homo sapiens, and expresses regret at the rejection by Sir Arthur Keith of those claims. In this connexion, reference may be made to Nature of October 15,1938 , p. 694, where there is an account of the Podkumok skull, and of Sir A. Keith's opinion. The whole article, which deals, however, with European Russia, demands reference in this place, more particularly in connexion with Prof. Bunak's report in VOKS (1945).

\section{W. L. H. DUCKWORTH}

